\title{
Real-Time Correction: Using Analytic Data to Improve the Learning Process: Insights from Development Negotiation Management MOOC
}

\author{
Orna Barness Kopolovich \\ HIT Holon Institute of Technology, Israel
}

\begin{abstract}
Learning soft skills through a MOOC course for Life-long Learners is very challenging. First, it requires transferring theoretical knowledge to practice through the development of simulations recreating life situations.

Secondly, the development of the content takes into account ways of maintaining high levels of independent learning and motivation.

Thirdly, a Life-long learners course is built to match diverse audiences in different age ranges, with different prior knowledge and different technological orientations.

The technological innovations of recent years enable us to simultaneously, monitor the learning process through analytical applications (data mining) that provide real-time information about the learning patterns of large and heterogeneous groups of learners, and also enable us to evaluate the degree of involvement in learning and predict the chances of success in the course.

However, the best combination of the analysis tools in the instructional-studies process is at its inception, especially in the collection and analysis of ongoing data throughout the learning period, and the concentration of insights that will enable practical advice to improve the process of teaching and learning.

This work focuses on data analytical insights from a MOOC in negotiation management, attended by approximately six thousand students over six months. The result was an improved teaching and learning experience.

The course opens with an innovative approach of edutainment (Educational Entertainment, presenting life-negotiation situations.

The content of the course is in mini-case format, based on the principle of sitcoms; a series of episodes that follow the lives of four characters and a turnover of supporting actors. After each episode, the situations are abstracted and generalized to daily uses of negotiation practices; the lecturer then further analyses them through models and concepts learned in the course. The discourse between the characters includes negotiating situations, which entice authentic learning
\end{abstract}




\section{International Conference on Innovative Research in}

\section{6-28 July, 2019}

\section{EDUCATION}

LONDON, UNITED KINGDOM

by inspiring curiosity and interest in the life of the characters. Ultimately, the purpose is to create a strong emotional engagement that keeps motivation levels around the content of the course high because the student can fully identify to the simulations.

Following are some examples of how the Analytic applications helped us analyze the learning patterns in real-time and maintain the high involvement of the learners.

The Analytic applications mediate at the rendez-vous point between technology and education, and enable us to produce innovative and interactive content for large audiences.

Keywords: Analytic Data, Lifelong Learning, MOOC, Soft Skills, Negotiation Management 